\title{
Homo- and Heterodinuclear Iron Clathrochelate Complexes with Functional Groups in the Ligand Periphery
}

\author{
José L. Bila, ${ }^{[a]}$ Mathieu Marmier, ${ }^{[a]}$ Konstantin O. Zhurov, ${ }^{\left[{ }^{[a]}\right.}$ Rosario Scopelliti, ${ }^{\left[{ }^{[a]}\right.}$ Ivica Živković, ${ }^{[b]}$ Henrik \\ M. Rønnow, ${ }^{[b]}$ Elahi S. Noore, ${ }^{[b]}$ Andrzej Sienkiewicz, ${ }^{[b]}$ Cornel Fink, ${ }^{[a]}$ and Kay Severin ${ }^{*[a]}$
}

\begin{abstract}
Dinuclear iron clathrochelate complexes were prepared by metal-templated condensation reactions of 4-pyridylboronic acid and phenol dioximes in the presence of $\mathrm{Fe}^{\mathrm{III}}$ and/or Fe"l salts. The complexes are accessible in two distinct redox states, featuring either two $\mathrm{Fe}^{\prime \prime}$ centers or a mixed-valence $\mathrm{Fe}^{\prime \prime} / \mathrm{Fe} \mathrm{e}^{\mathrm{III}}$ state. It is possible to reversibly switch between the two forms by chemical oxidation/reduction or electrochemically. A heterometallic $\mathrm{Zn}^{\prime \prime} / \mathrm{Fe}^{\text {III }}$ clathrochelate was obtained by using a mixture of zinc and iron salts. All complexes feature terminal pyridyl groups, which makes them interesting building blocks for metallasupramolecular chemistry. Metal ion exchange reactions indicate that the iron clathrochelate complexes are thermodynamically more stable than the analogous zinc and cobalt complexes. The high stability allowed to prepare a clathrochelate polymer by palladium-catalyzed polycross-coupling of a polybrominated clathrochelate complex with 1,4-benzenediboronic acid. The polymer network displays permanent porosity with an apparent Brunauer-Emmett-Teller surface area of $S A_{B E T}=510 \mathrm{~m}^{2} \mathrm{~g}^{-1}$. The polymer is thermally stable and not susceptible to hydrolytic degradation.
\end{abstract}

\section{Introduction}

Dinuclear clathrochelate complexes can be obtained by combining a divalent metal ion, a boronic acid, and a phenol dioxime ligand (Scheme 1). ${ }^{[1]}$ The six-fold condensation reaction gives boronate ester-capped complexes with two hexacoordinate $\mathrm{M}^{\prime \prime}$ ions in the center. The macrobicyclic ligand has a formal charge of minus five, resulting in a net charge of minus one for the entire complex. A first example of such a dinuclear clathrochelate complex was reported by Chaudhuri and coworkers in 2006. ${ }^{[2]}$ They used $\mathrm{Mn}^{2+}$ as metal template and methylboronic acid as capping agent. The clathrochelate was synthesized in order to study its magnetic properties. Our group has investigated dinuclear clathrochelates in a completely different context, namely as building blocks in

[a] J. L. Bila, Dr. M. Marmier, Dr. K. O. Zhurov, Dr. R. Scopelliti, Cornel Fink, Prof. K. Severin

Institut des Sciences et Ingénierie Chimiques

École Polytechnique Fédérale de Lausanne (EPFL)

1015 Lausanne, Switzerland

E-mail: kay.severin@epfl.ch

[b] Dr. Ivica Živković, Prof. Henrik M. Rønnow, Dr. Andrzej Sienkiewicz Institute of Physics, EPFL

Supporting information for this article is given via a link at the end of the document. metallasupramolecular chemistry. In a first publication in 2014, we have reported that dinuclear clathrochelates can be decorated with 4-pyridyl groups in axial position. ${ }^{[3]}$ The functionalization with $\mathrm{N}$-donor groups was achieved by using 4-pyridylboronic acid during the preparation of the complexes. We were able to show that these functionalized clathrochelates can be used as metalloligands ${ }^{[4]}$ for the construction of metallomacrocycles and metal-organic frameworks. ${ }^{[3]}$ Subsequently, we have prepared dinuclear clathrochelate complexes with different functional groups (e.g. $\mathrm{CN}$ and $\mathrm{CO}_{2} \mathrm{H}$ ) in the ligand periphery. ${ }^{[5]}$ Again, they were found to very useful building blocks for the synthesis of metallosupramolecular architectures. So far, we have focused our investigation on dinuclear clathrochelates containing either $\mathrm{Zn}^{2+}$, $\mathrm{Co}^{2+}$ or $\mathrm{Mn}^{2+}$ ions. Below, we show that iron clathrochelate complexes can be prepared as well. These complexes are accessible in two distinct redox states, and they display an increased thermodynamic stability. Both features are attractive for applications in supramolecular chemistry and materials science.

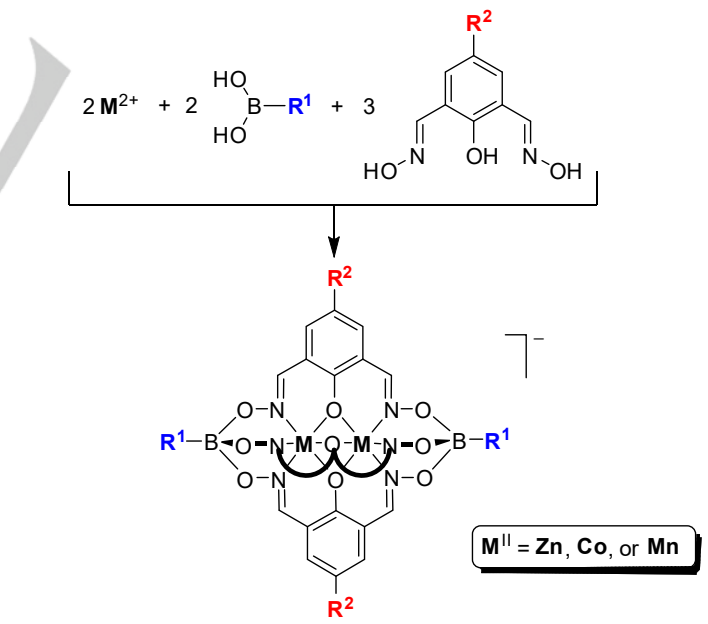

Scheme 1. Synthesis of dinuclear clathrochelate complexes containing $\mathrm{Zn}^{2+}$, $\mathrm{Co}^{2+}$, or $\mathrm{Mn}^{2+}$ (refs 1-3,5). Functional groups can be introduced via the substituents $\mathrm{R}^{1}$ and $\mathrm{R}^{2}$

\section{Results and Discussion}

During our previous investigations, we had made observations, which suggest that Co"-based clathrochelates are more stable than their $\mathrm{Zn}^{\|}$analogues. For example, we were able to employ $\mathrm{Co}$ " clathrochelates as metalloligands for the synthesis of MOFs, 
whereas the analogous $\mathrm{Zn}$ " complexes did not give satisfactory results (presumably due to decomposition). In order to study the issue of stability in more detail, we decided to perform metal ion exchange reactions. A solution of the $\mathrm{Zn}^{\text {"l }}$ clathrochelate 1 in methanol was heated in the presence of an excess (20 equiv.) of $\left.\left[\mathrm{Co}\left(\mathrm{H}_{2} \mathrm{O}\right)_{6}\right]\left(\mathrm{NO}_{3}\right)_{2}\right]$. After $12 \mathrm{~h}$, the solution was analyzed by high resolution ESI mass spectrometry (HRMS). The MS data indicated a clean and complete metal ion exchange to the Co" clathrochelate 2 (Scheme 2). We have also performed the inverse experiment, i.e. a solution of the $\mathrm{Co}$ " clathrochelate $\mathbf{2}$ was heated with an excess of $\mathrm{Zn}(\mathrm{OTf})_{2}$, but no metal ion exchange was observed. These results corroborated our assumption that the $\mathrm{Co}^{\text {"l }}$ clathrochelates are more stable than the $\mathrm{Zn}$ clathrochelates. Subsequent studies revealed that metal ion exchange reactions can also be performed with $\mathrm{Fe}^{\prime l}$ (Scheme 2). Heating of a methanol solution of 1 with an excess of $\left[\mathrm{Fe}\left(\mathrm{H}_{2} \mathrm{O}\right)_{6}\right]\left(\mathrm{ClO}_{4}\right)_{2}$ resulted in clean and complete metal ion exchange, as indicated by HRMS. The MS data also showed that a mixed valence $\mathrm{Fe}^{\text {II/Fe }}$ III complex had formed. Apparently, one of the Fe centers was oxidized during the exchange reaction. In a similar fashion, the Coll clathrochelate 2 could be converted into the mixed valence $\mathrm{Fe}^{\text {II/ }} / \mathrm{Fe}^{\text {III }}$ clathrochelate 3 by heating with $\left[\mathrm{Fe}\left(\mathrm{H}_{2} \mathrm{O}\right)_{6}\right]\left(\mathrm{ClO}_{4}\right)_{2}$ (Scheme 2).

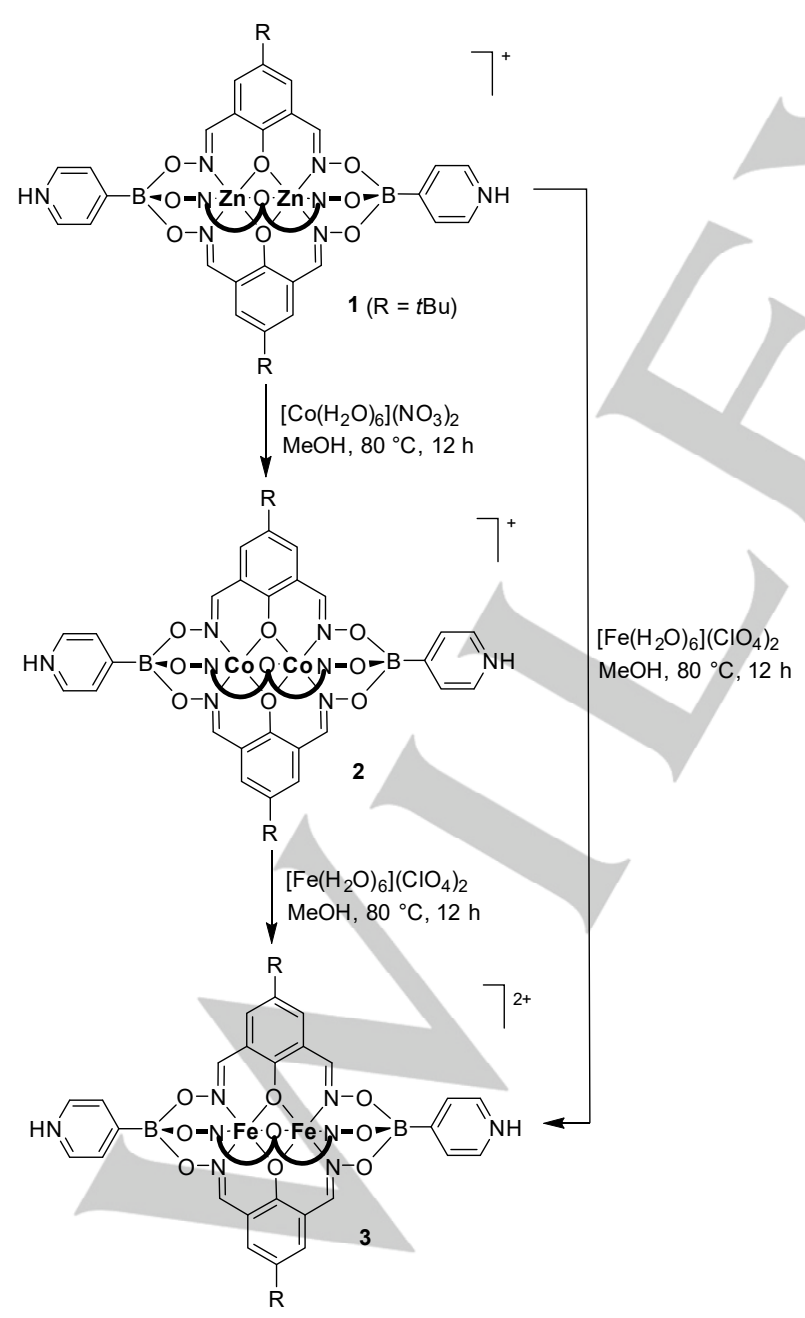

Scheme 2. Metal ion exchange reactions in dinuclear clathrochelate complexes.

Two different mechanisms for the metal ion exchange can be envisioned: a) the exchange occurs with an intact macrobicyclic ligand framework, or b) the exchange requires reversible cleavage of the ligand framework. Such a rupture could occur via solvolysis of the $\mathrm{B}-\mathrm{O}$ bond.

To distinguish the two possible mechanisms, we have performed a metal-exchange reaction using two different $\mathrm{Zn}$ " clathrochelates (Scheme 3). After heating the mixture with $\left[\mathrm{Fe}\left(\mathrm{H}_{2} \mathrm{O}\right)_{6}\right]\left(\mathrm{ClO}_{4}\right)_{2}$ in methanol, we were able to observe metal ion exchange and ligand scrambling by HRMS. We therefore conclude that the $\mathrm{Zn} \rightarrow \mathrm{Fe}$ exchange most likely occurs via a dissociate mechanism involving rupture of the macrobicyclic ligand framework.
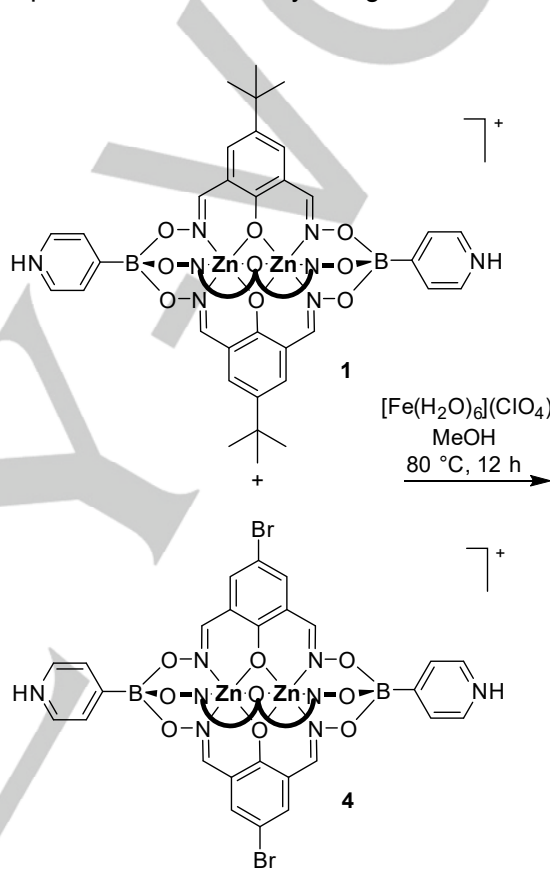

Scheme 3 . Heating a mixture of the $\mathrm{Zn}$ clathrochelates $\mathbf{1}$ and $\mathbf{2}$ with an excess of an $\mathrm{Fe}^{\mathrm{Il}}$ salt results in metal ion exchange and scrambling of the dioxime part of the ligand.

Next, we investigated the direct preparation of Fe clathrochelate complexes. As metal salt, we employed $\mathrm{Fe}(\mathrm{OTf})_{3}$ and/or $\mathrm{Fe}(\mathrm{OTf})_{2}$. 4-Pyridylboronic acid was chosen as capping agent, because the resulting complexes could potentially be used as metalloligands. In addition to a phenol dioxime ligand with a solubilizing tert-butyl side chain, we have employed a phenol dioxime with an electronwithdrawing bromo substituent.

When the condensation reaction was performed with $\mathrm{Fe}(\mathrm{OTf})_{2}$ under strictly anaerobic conditions, we were able to isolate the $\mathrm{Fe}^{\prime \prime} / \mathrm{Fe}$ " clathrochelate complexes $\mathbf{5}$ and $\mathbf{6}$ in good yields (Scheme 4). However, when the reactions were performed in the presence of air, oxidation to the Fe"/Fe $\mathrm{e}^{\text {III }}$ complexes $\mathbf{7}$ and $\mathbf{8}$ was observed. The mixed-valence complexes can be prepared cleanly if an equimolar mixture of $\mathrm{Fe}(\mathrm{OTf})_{3}$ and $\mathrm{Fe}(\mathrm{OTf})_{2}$ is used (Scheme 4). Notably, we were not able to prepare a Fe $\mathrm{e}^{\prime \prime \prime} / \mathrm{Fe} \mathrm{e}^{\mathrm{III}}$ clathrochelate by exclusively using $\mathrm{Fe}(\mathrm{OTf})_{3}$. 


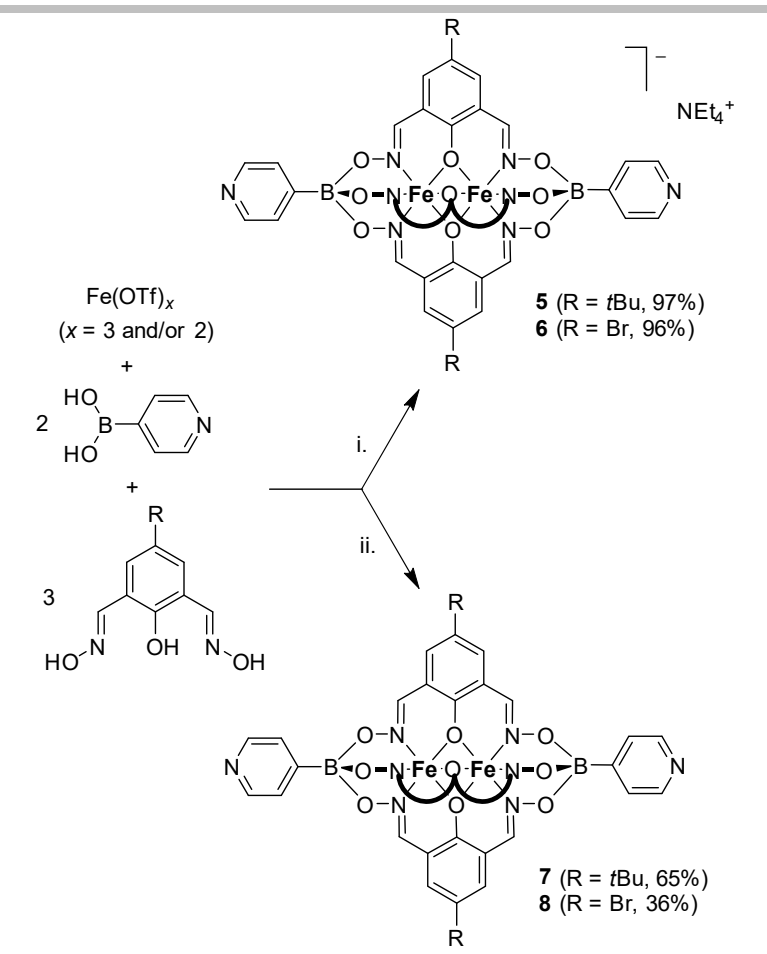

Scheme 4. Synthesis of the Fe clathrochelate complexes 5-8. Conditions: i: $\mathrm{MeOH}, 50^{\circ} \mathrm{C}, 1 \mathrm{~h}$, then $\mathrm{MeOH} / \mathrm{EtOH}, \mathrm{NEt}_{4} \mathrm{OH}, \mathrm{RT}, 1 \mathrm{~h}$; ii: $\mathrm{MeOH}, 60^{\circ} \mathrm{C}, 2 \mathrm{~h}$, then $\mathrm{NEt}_{4} \mathrm{OH}, \mathrm{RT}, 1 \mathrm{~h}$

The new clathrochelate complexes 5-8 were analyzed by single crystal X-ray diffraction (complex 7 as a double HOTf adduct). As expected, the $\mathrm{Fe}$ ions coordinate the oximato $\mathrm{N}$-atoms and to the bridging phenolato O-atoms (Figure 1). For all four complexes, the coordination geometry around the iron centers can be described as trigonal prismatic. A similar geometry is observed for dinuclear clathrochelates based on $\mathrm{Zn}^{\prime \prime}, \mathrm{Mn}^{\|}$or $\mathrm{Co}^{\| \prime},{ }^{13,5,6]}$ and for mononuclear $\mathrm{Fe}^{\| l}$ clathrochelate complexes. ${ }^{[1,7]}$ The mixedvalence complexes 7 and 8 feature shorter average $\mathrm{Fe}-\mathrm{O}$ bonds compared to the $\mathrm{Fe}^{\prime \prime} / \mathrm{Fe}$ " complexes 5 and $\mathbf{6}$ (Table 1). As a result, the Fe..*Fe distances are shorter for the oxidized complexes. The average $\mathrm{Fe}-\mathrm{N}$ bond distances, on the other hand, are similar for the all four complexes. It is worth noting that two Fe centers in the mixed-valence complexes $\mathbf{7}$ and $\mathbf{8}$ cannot be distinguished crystallographically.

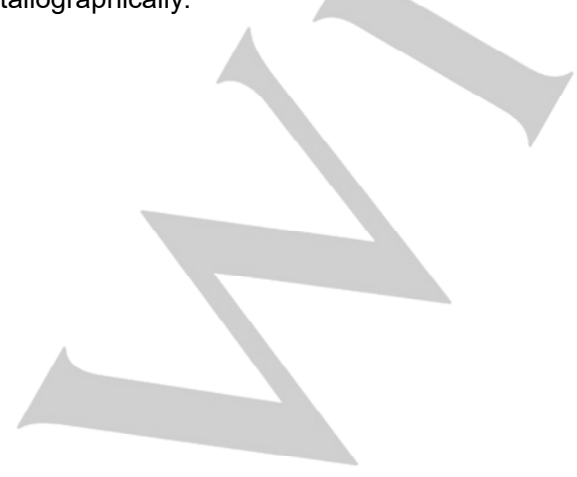

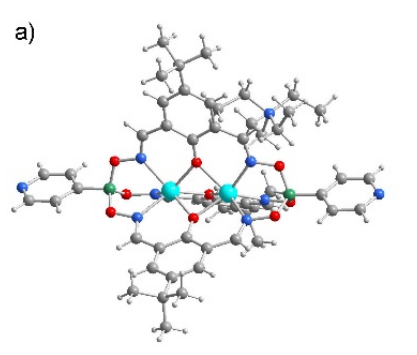
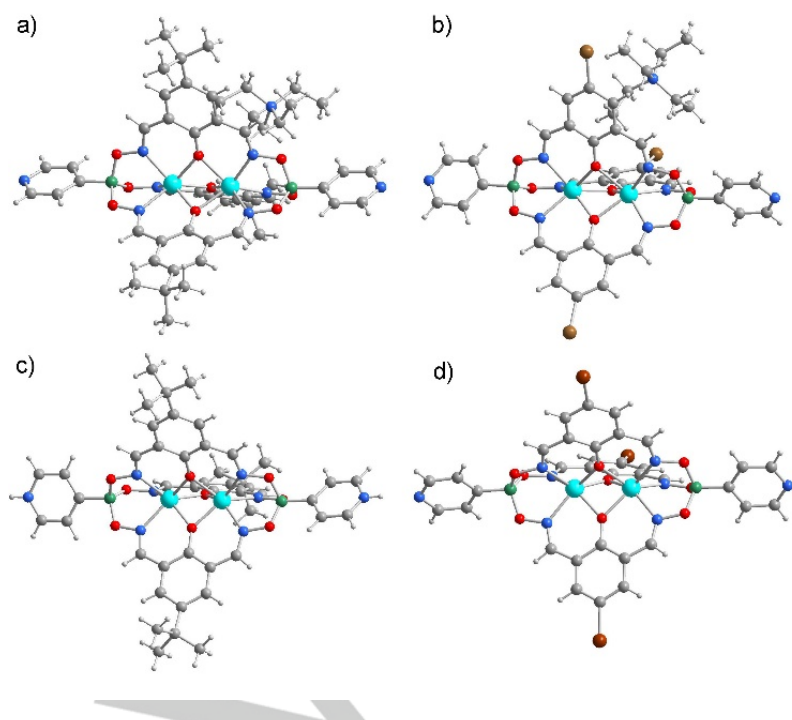

d)

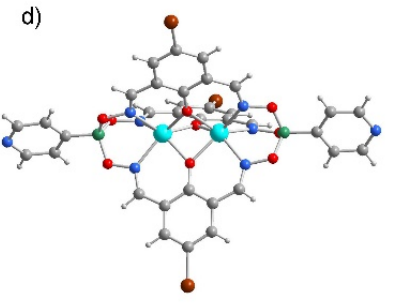

Figure 1. Molecular structures of the complexes 5 (a), 6 (b), and $\mathbf{7}(\mathrm{HOTf})_{2}$ (c), and 8 (d) in the crystal. Co-crystallized solvent molecules and the (OTf) $)^{-}$anions (7) are not shown for clarity. Color coding: C (gray), $\mathrm{H}$ (light gray), Fe (cyan), N (blue), $\mathrm{O}$ (red), $\mathrm{Br}$ (brown), and $\mathrm{B}$ (green).

Table 1. Selected bond distances $[\AA]$ and angles $\left[{ }^{\circ}\right]$ for the complexes 5,6 , $\mathbf{7}(\mathrm{HOTf})_{2}, 8$ and 10

\begin{tabular}{lllll}
\hline Complex $^{[a]}$ & $\mathrm{Fe}-\mathrm{O}_{\mathrm{av}}$ & $\mathrm{Fe}-\mathrm{N}_{\mathrm{av}}$ & $\mathrm{Fe} \cdot \cdots \cdot \mathrm{Fe}$ & $\mathrm{O}-\mathrm{Fe}-\mathrm{N}_{\mathrm{av}}$ \\
\hline $\mathbf{5}$ & 2.10 & 2.13 & $2.905(1)$ & 81.8 \\
$\mathbf{6}$ & 2.11 & 2.13 & $2.925(1)$ & 81.8 \\
$\mathbf{7 ( \mathrm { HOTf } ) _ { 2 }}$ & 2.04 & 2.13 & $2.761(1)$ & 81.8 \\
$\mathbf{8}$ & 2.04 & 2.13 & $2.766(1)$ & 82.2 \\
$\mathbf{1 0}$ & 2.04 & 2.13 & $2.772(1)$ & 82.3
\end{tabular}

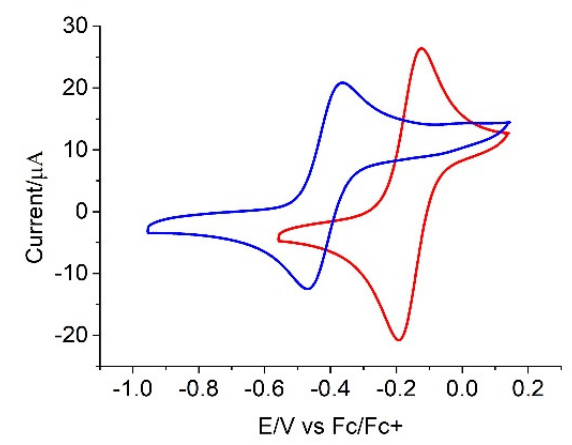

Figure 2. Cyclic voltammograms of solutions containing complexe 5 (blue line) or 6 (red line). Conditions: solvent: $\mathrm{DMF}$, electrolyte: $\mathrm{NBu}_{4} \mathrm{PF}_{6}$, scan rate: $100 \mathrm{mV} \mathrm{s}^{-1}$.

The redox behavior of the complexes 5 and $\mathbf{6}$ was investigated by means of cyclic voltammetry (CV) in DMF under inert atmosphere. 
Both compounds show a reversible one electron oxidation at negative potential versus a ferrocene/ferrocenium $\left(\mathrm{Fc} / \mathrm{Fc}^{+}\right)$ reference (Figure 2). The substituents in para-position to the phenolato group have a pronounced influence on the redox potential, with a difference of $253 \mathrm{mV}$ between the bromo complex $6\left(E_{1 / 2}=-0.158 \mathrm{~V}\right)$ and the $t$-Bu complex $5\left(E_{1 / 2}=-0.411 \mathrm{~V}\right)$.

The reversible redox chemistry observed by cyclic voltammetry prompted us to explore the chemical interconversion of the $\mathrm{Fe}^{\prime \prime} / \mathrm{Fe} \mathrm{I}^{\prime \prime}$ complexes 5 and $\mathbf{6}$ and the mixed-valence $\mathrm{Fe} / 1 / \mathrm{Fe}^{\mathrm{III}}$ complexes 7 and $\mathbf{8}$. We found that the $\mathrm{Fe}^{\prime \prime} / \mathrm{Fe}$ "l complexes can be oxidized to by hydrogen peroxide, whereas their reduction was achieved by sodium dithionite (Scheme 5 ). The reactions can be followed by UV-vis spectroscopy, because the oxidized complexes have characteristic absorption bands at 525 and $700 \mathrm{~nm}$. In addition, we used ESI mass spectrometry for reaction analysis, because the reduced complexes are detected in the negative mode (they have an overall charge of minus 1 ), whereas the oxidized complexes are detected in the positive mode.
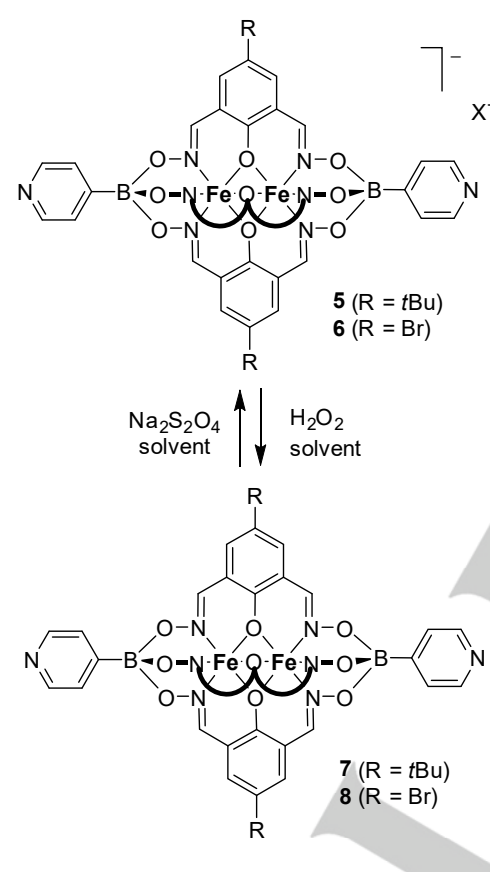

Scheme 5. Interconversion of the Fe"/Fe" complex 5 and $\mathbf{6}$ and the $\mathrm{Fe}^{\prime \prime} / \mathrm{Fe}^{\mathrm{III}}$ complex 7 and 8 by chemical oxidation or reduction, respectively.

The magnetic properties of the iron clathrochelate complexes was investigated using 6 and 8 as representative examples. The magnetic susceptibility $v s$ temperature were measured in the temperature range of $5-350 \mathrm{~K}$ with an applied field of $1 \mathrm{~T}$ and Zero Field Cooling (ZFC). The susceptibility of 6 containing $\mathrm{Fe}^{\prime \prime} / \mathrm{Fe}$ "l shows a broad maximum around $40 \mathrm{~K}$ and decreases at higher temperatures (Figure 3). We model the behavior following a simple Hamiltonian $H=J \cdot S_{1} \cdot S_{2}$, where $J$ represents the exchange interaction between two $\mathrm{Fe}^{\prime \prime}$ magnetic moments $(S=2)$. Rather good agreement has been achieved with an antiferromagnetic coupling between the moments of $J=14 \mathrm{~K}$. If the high temperature part is fitted with a Curie-Weiss behavior $\left(\chi_{\mathrm{m}}\right.$ $\left.=C /(T-T \mathrm{c})+\chi_{0}\right)$, one obtains a Curie constant of $C=3.18 \mathrm{emu} \mathrm{K}$ $\mathrm{mol}^{-1}$ per $\mathrm{Fe}^{2+}$ which is in good agreement with the theoretical value of $C=3.0$ emu $\mathrm{K} \mathrm{mol}^{-1}$.

a)

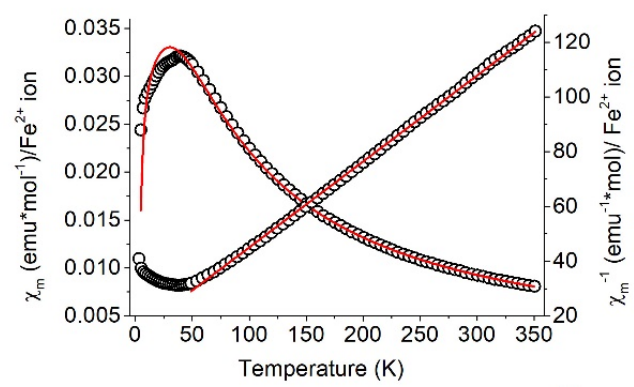

b)

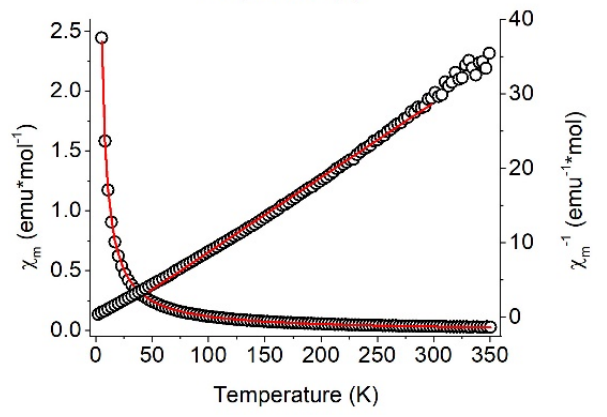

Figure 3. The magnetic susceptibility of the complexes $\mathbf{6}(\mathrm{a})$ and $\mathbf{8}(\mathrm{b})$ as a function of temperature (the red curves are indicate the fit).

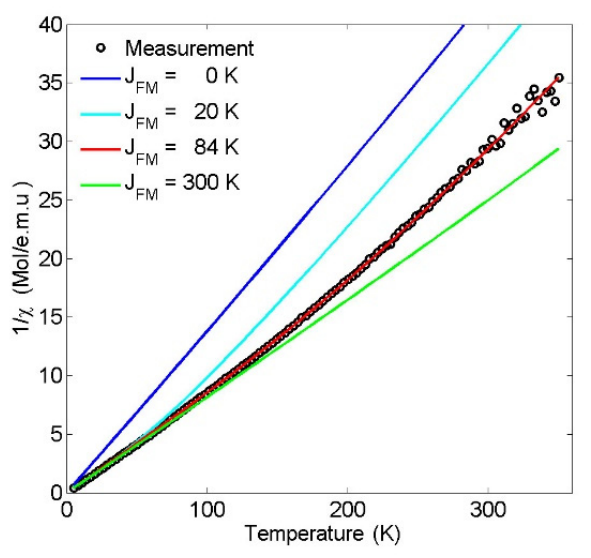

Figure 4. The magnetic susceptibility of complex 8 as a function of temperature. Lines indicate susceptibility calculated for a $S=2$ and a $S=5 / 2$ coupled with various values of ferromagnetic coupling $J_{F M}$.

The inverse susceptibility of compound 8 containing Fe"/Fe"II increases monotonically with temperature from 5 to $350 \mathrm{~K}$ with a slight upwards curvature. The low temperature slope corresponds to a Curie constant of $12.6 \mathrm{emu} \mathrm{K} \mathrm{mol}{ }^{-1}$, which relates to a paramagnetic spin $S=9 / 2$ and a $g$-factor around 2 . This implies that at low temperature, the Fe"l $S=2$ and $\mathrm{Fe}^{\mathrm{III}} S=5 / 2$ are coupled strongly ferromagnetically to a single $S=9 / 2$ moment. However, as indicated by the calculated lines, the upwards curvature indicates that this ferromagnetic coupling is finite. We 
note that the values of $J_{\mathrm{FM}}$ and $\chi_{0}$ extracted from the fit are strongly coupled. Given the similarity of the complexes we therefore kept $\chi_{0}$ fixed to the value obtained for complex $\mathbf{6}$, which yielded $J_{\mathrm{FM}}=84(7) \mathrm{K}$.

The observation of antiferromagnetic coupling between equal valence $\mathrm{Fe}^{\prime \prime}(S=2)$ ions in complex 6 and ferromagnetic coupling

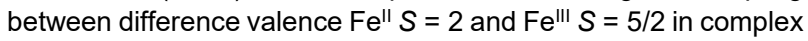
8 agrees with what would be expected from respectively exchange and super-exchange interactions.

Next, we have investigated the possibility to synthesize heterobimetallic clathrochelate complexes. For this purpose, we have performed the condensation reaction with an equimolar mixture of $\mathrm{Zn}(\mathrm{OTf})_{2}$ and $\mathrm{Fe}(\mathrm{OTf})_{3}$. As ligand precursors, we have employed a $t$-Bu-substituted phenol dioxime and 3-pyridylboronic acid. ${ }^{[8]}$ The reaction with two different metal salts was expected to give the homobimetallic $\mathrm{Zn}$ " clathrochelate along with the desired $\mathrm{Zn}^{\prime \prime} / \mathrm{Fe} \mathrm{e}^{\mathrm{III}}$ complex. However, these two complexes have a different overall charge, which should facilitate separation. The formation

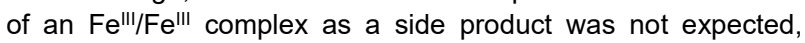
because such a complex could not be obtained from Fe $\mathrm{e}^{\text {III }}$ salts (see above).

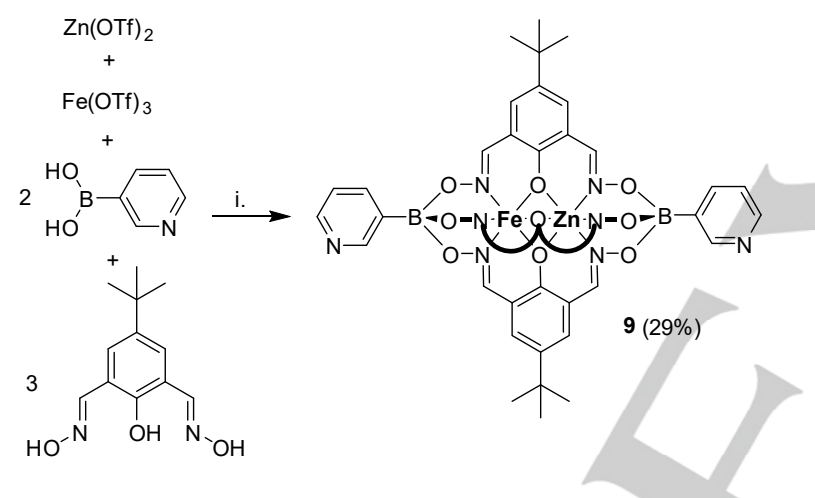

Scheme 6. Synthesis of the heterobimetallic $\mathrm{Zn}^{\prime \prime} / \mathrm{Fe}^{\mathrm{III}}$ clathrochelate 9. Conditions: i: $\mathrm{MeOH}: \mathrm{DCM}(1: 1) 70^{\circ} \mathrm{C}, 2 \mathrm{~h}$; then $\mathrm{NEt}_{4} \mathrm{OH}, 1 \mathrm{~h}$.

Following the procedure outlined above, we were indeed able to obtain the heterobimetallic complex $\mathbf{9}$ after purification by column chromatography (Scheme 6). The molecular structure of complex 9 in the solid state was determined by single crystal X-ray diffraction (Figure 5). The Fe $\mathrm{F}^{\mathrm{III}}$ and $\mathrm{Zn}$ " ions are disordered over both sites, and the average $\mathrm{M}-\mathrm{N}(2.08 \AA)$ and $\mathrm{M}-\mathrm{O}$ bond lengths $(2.11 \AA)$ are comparable to what was observed for the homobimetallic Fe clathrochelates.

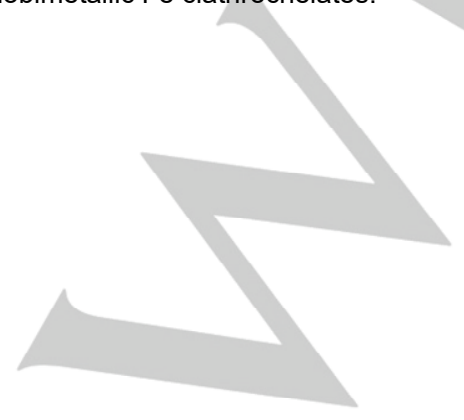

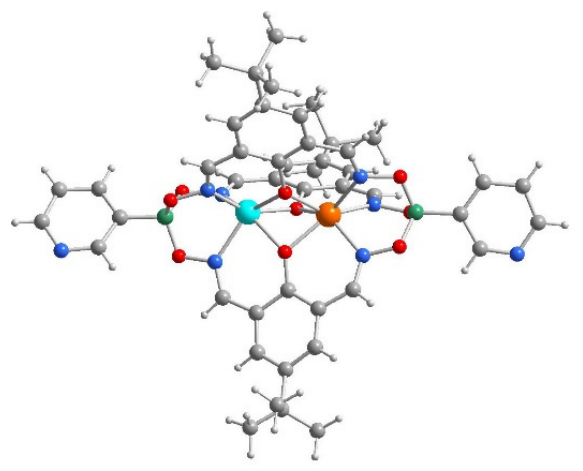

Figure 5. Molecular structure of the heterobimetallic complex 9 in the crystal. Color coding: C (gray), H (light gray), Fe (cyan), Zn (orange), N (blue), O (red), $\mathrm{Br}$ (brown), and B (green).

The high apparent stability of the Fe clathrochelate complexes prompted us to explore applications in materials science. In particular, we were interested if the cage complexes could be used as inorganic building blocks for the preparation of microporous polymers. Microporous polymers can be obtained by metal-catalyzed carbon-carbon coupling reactions of rigid, polyfunctional monomers. ${ }^{[8]}$ Depending on the nature of the monomers, the resulting polymers are classified as "porous aromatic frameworks" (PAFs) $)^{[8, f]}$ or "conjugated microporous polymers" (CMPs). ${ }^{[8, g]}$ Most studies in this area have focused on organic monomers, even though inorganic monomers are potentially interesting alternatives. ${ }^{[9]}$ A prerequisite of using inorganic monomers for the synthesis of PAFs or CMPs is their stability under polymerization conditions. This criterion is not trivial, because transition metal-catalyzed C-C coupling reactions are often performed under rather harsh reaction conditions. If metal complexes are employed as functional monomers, there is also the inherent danger of ligand and/or metal ion exchange reactions involving the coupling catalyst (typically: Pd-phosphine complexes).

We have recently shown that polybrominated $\mathrm{Zn}^{\prime \prime} / \mathrm{Zn}^{\prime \prime}$ clathrochelates can be functionalized by Pd-catalyzed crosscoupling reactions with boronic acids. ${ }^{[5 d]}$ Despite the apparent compatibility with cross-coupling conditions, we were not able to make porous polymers from $\mathrm{Zn}^{\prime \prime} / \mathrm{Zn}$ " clathrochelates. The higher stability of the $\mathrm{Fe}^{\prime \prime} / \mathrm{Fe} \mathrm{F}^{\mathrm{III}}$ complexes, along with the fact that they are charge-neutral, suggested that they are potentially more suited for this purpose. We therefore synthesized the pentabrominated $\mathrm{Fe}^{\text {II/Fe }}$ III clathrochelate 10 using a brominated phenol dioxime along with 4-bromophenylboronic acid. The five bromo functions of $\mathbf{1 0}$ are arranged in a trigonal bipyramidal fashion, as evidenced by a crystallographic analysis (Figure 6). 


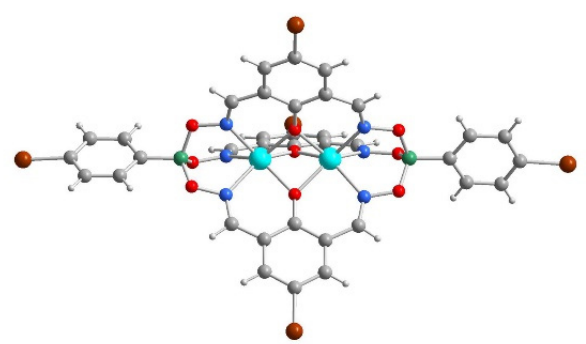

Figure 6. Molecular structure of the pentabrominated complex 10 in the crystal. Color coding: C (gray), H (light gray), Fe (cyan), N (blue), O (red), $\mathrm{Br}$ (brown), and $B$ (green).

In order to prepare a polymeric network, we have performed a polycross-coupling reaction of 10 with 1,4-benzenediboronic acid. The utilization of 1,4-dioxane: $\mathrm{H}_{2} \mathrm{O}(4: 1)$ as solvent was found to be advantageous. As catalyst precursor, we have employed $\mathrm{Pd}\left(\mathrm{PPh}_{3}\right)_{4} \quad(10 \mathrm{~mol} \%$ with respect to the boronic acid) in combination with $\mathrm{K}_{2} \mathrm{CO}_{3}$ as base. A molar ratio of 3:1 between the diboronic acid and the brominated clathrochelate was found to give polymers with the highest porosity. Most likely, the excess of boronic acid is needed to compensate for protodeboronation reactions. ${ }^{[10]}$ Using these conditions, we prepared the porous clathrochelate polymer PCP-1 by heating the reaction mixture at $110{ }^{\circ} \mathrm{C}$ for $12 \mathrm{~h}$ (Scheme 7). ${ }^{[11]}$

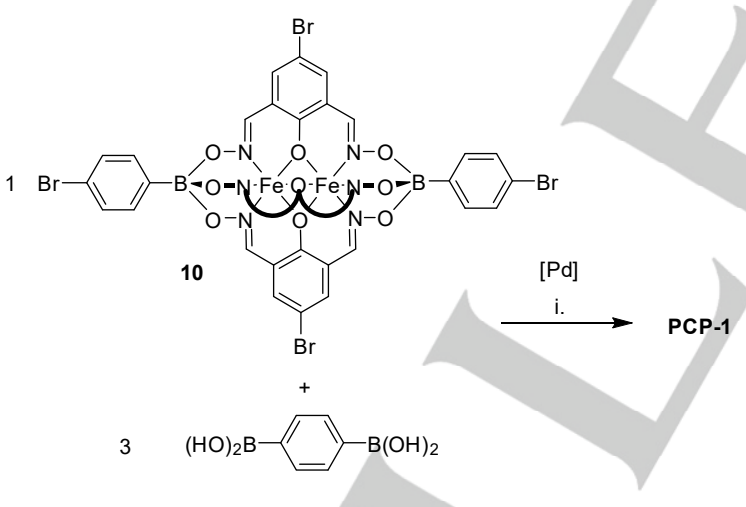

Scheme 7. Synthesis of the porous clathrochelate polymer PCP-1. Conditions: i: 1,4-dioxane: $\mathrm{H}_{2} \mathrm{O}(4: 1), \mathrm{K}_{2} \mathrm{CO}_{3}, \mathrm{Pd}\left(\mathrm{PPh}_{3}\right)_{4}, 110{ }^{\circ} \mathrm{C}, \mathrm{N}_{2}, 12 \mathrm{~h}$.

PCP-1 was characterized by thermogravimetric analysis (TGA), $\mathrm{N}_{2}, \mathrm{H}_{2}$, and $\mathrm{CO}_{2}$ physisorption measurements, Fourier-transform infrared spectroscopy (FT-IR), and scanning electron microscopy (SEM). The $\mathrm{N}_{2}$ sorption measurements at $77 \mathrm{~K}$ were used to calculate an apparent Brunauer-Emmett-Teller (BET) surface area of $S A_{B E T}=510 \mathrm{~m}^{2} \mathrm{~g}^{-1}$ (Figure 7a), and nonlocal density functional theory revealed micropores of $1.2 \mathrm{~nm}$ in diameter (Figure $7 \mathrm{c}$ ). The $\mathrm{H}_{2}$ and $\mathrm{CO}_{2}$ isotherms were measured at $77 \mathrm{~K}$ and $273 \mathrm{~K}$, respectively (Figure $7 \mathrm{~b}$ and Figure S17). These measurements showed that PCP-1 has a $\mathrm{H}_{2}$ uptake capacity of $98 \mathrm{~cm}^{3} \mathrm{~g}^{-1}$ and a $\mathrm{CO}_{2}$ uptake capacity of $61 \mathrm{~cm}^{3} \mathrm{~g}^{-1}$ (both at
1.0 bar). The porosity and the $\mathrm{H}_{2} / \mathrm{CO}_{2}$ uptake of PCP-1 is within the range observed for many other PAFs and CMPs. ${ }^{[8,9]}$ An SEM image of PCP-1 shows irregular spherical aggregates as expected for cross-linked polymers (Figure 7d). Similar to complex 10, polymer PCP-1 is paramagnetic, and the magnetic susceptibility can be fitted with a Curie behavior (Figure S15). TGA measurements (Figure S13) revealed a good thermal stabilities up to $250{ }^{\circ} \mathrm{C}$, and no loss in porosity was observed when a suspension of PCP-1 was heated at $80^{\circ} \mathrm{C}$ for $6 \mathrm{~h}$ in $\mathrm{H}_{2} \mathrm{O}$.

$$
\text { a) }
$$
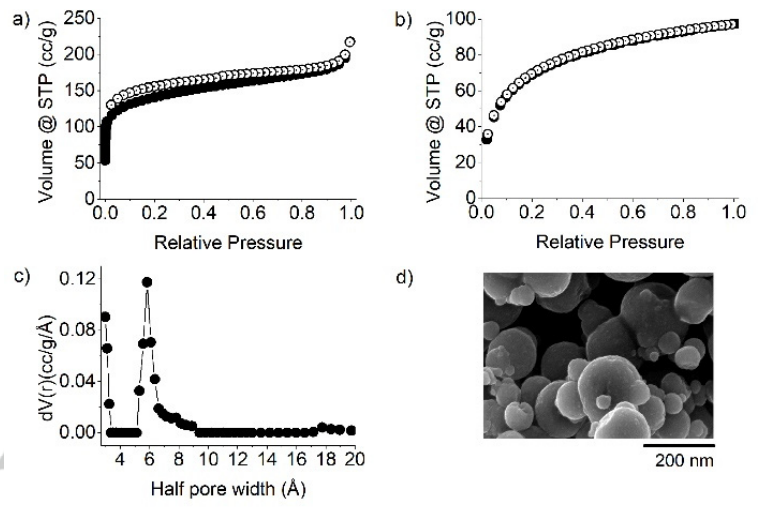

Figure 7. Characterization of PCP-1: a) $\mathrm{N}_{2}$ adsorption (filled symbols) and desorption (open symbols) isotherms at $77 \mathrm{~K}$; b) $\mathrm{H}_{2}$ adsorption (filled symbols) and desorption (open symbols) isotherms at $77 \mathrm{~K}$; c) Pore size distribution; d) SEM image of PCP-1.

\section{Conclusions}

Dinuclear iron clathrochelate complexes can be obtained by condensation reactions of boronic acids and phenol dioximes in the presence of iron salts. The complexes are accessible in two different oxidation states ( $\mathrm{Fe}^{\prime \prime} / \mathrm{Fe}^{\| \prime}$ and $\left.\mathrm{Fe}^{\| 1 /} / \mathrm{Fe}^{\mathrm{III}}\right)$, and switching between the states is possible, either chemically or electrochemically. The utilization of pyridylboronic acids results in the formation of cage complexes with apical pyridyl groups. These complexes could be used as redox-switchable metalloligands in supramolecular coordination chemistry. Another noteworthy characteristic is the increased stability of the $\mathrm{Fe}^{\prime \prime} / \mathrm{Fe}{ }^{\text {III }}$ clathrochelates compared to the previously described $\mathrm{Zn} / / \mathrm{Zn}^{\prime \prime}$ and $\mathrm{Co} / \mathrm{Co}$ " complexes. This feature makes them interesting building blocks for applications in materials science. As a first step in this direction, we have shown that a polybrominated $\mathrm{Fe}^{\prime \prime} / \mathrm{Fe}^{\text {III }}$ clathrochelate can be used to prepare a porous polymer network, with good thermal and chemical stability. Similar to redox-active metal-organic frameworks, ${ }^{[12]}$ porous polymers based on redoxactive clathrochelate complexes may find applications in the area of energy storage or sensing.

\section{Experimental Section}

General: The measurements of the cyclic voltammetry were conducted under $\mathrm{N}_{2}$ atmosphere with a computer controlled voltammetry analyzer connected to three electrodes. Working 
electrode (carbon), Reference electrode $(\mathrm{Ag}, \mathrm{AgCl})$, and counter electrode (Pt wire). The electrodes were immersed in a DMF solution containing $\approx 5 \mathrm{mg} / \mathrm{mL}$ of sample. Tetrabutylammonium hexafluorophosphate $(0.1 \mathrm{M})$ was used as electrolyte. The susceptibility measurements were carried out on a Quantum Design MPMS-XL 5T Superconducting Quantum Interference Device (SQUID) magnetometer. The samples were placed in a plastic capsule which was incorporated into two plastic straws as sample holder. The measurements were done with an applied field of $1 \mathrm{~T}$ and temperatures ranging from 5 to $350 \mathrm{~K}$ using the Zero Field Cooled method (ZFC). High resolution MS data were acquired on an Orbitrap Elite FTMS (Thermo Scientific) coupled to a nano-electrospray ionization source (TriVersa NanoMate, Advion) operated via Xcalibur software in positive ionization mode with resolution set to 120,000 at $400 \mathrm{~m} / \mathrm{z}$. Post-acquisition analysis involving isotopic distribution matching was done with aid of ChemCalc web tool (www.chemcalc.org). ${ }^{[13]}$ Additional electrospray-ionisation MS data were acquired on a Q-Tof Ultima mass spectrometer (Waters) operated in the positive and negative ionization modes using the ZSpray ${ }^{\mathrm{TM}}$ dual-orthogonal multimode $\mathrm{ESI} / \mathrm{APCI} / \mathrm{ESCi}{ }^{\circ}$ source and processed using the MassLynx 4.1 software. IR spectra were recorded on a Perkin Elmer Spectrum One Golden Gate FT/IR spectrometer. UV-vis spectra were recorded on an Agilent technologies, Cary-60 spectrophotometer. Nitrogen ( $77 \mathrm{~K})$, carbon dioxide (273 K), and hydrogen $(77 \mathrm{~K})$ sorption measurements were performed on a Quantachrome Autosorb iQ analyzer. Polymers PCP-1 was dried at $100{ }^{\circ} \mathrm{C}(5 \mathrm{~h})$ and $120^{\circ} \mathrm{C}(5 \mathrm{~h})$ before measurements. The surface area was calculated with BET assistant (built-in software) and a Rouquerol plot within the valid BET relative pressure range (0.05-0.30). Density functional theory (DFT) was used with $\mathrm{N}_{2}$ adsorption isotherms to calculate the pore size distribution and the cumulative pore volume. SEM measurements were performed on a Zeiss Merlin SEM. The thermogravimetric analyses were performed with a Perkin Elmer 4000 TGA between $30{ }^{\circ} \mathrm{C}$ and $700{ }^{\circ} \mathrm{C}$ with a nitrogen atmosphere at $20 \mathrm{~mL} \mathrm{~min}{ }^{-1}$ flowrate. The data were analyzed with Perkin Elmer Pyris software.

Complex 5: $\mathrm{Fe}(\mathrm{OTf})_{2}(113.6 \mathrm{mg}, 321 \mu \mathrm{mol})$ was added to a solution of 2,6-diformyl-4-tert-butyl-phenol dioxime (100 mg, $423 \mu \mathrm{mol})$ and 4-pyridylboronic acid $(39.5 \mathrm{mg}, 321 \mu \mathrm{mol})$ in $\mathrm{MeOH}(20 \mathrm{~mL})$ in the glovebox. The reaction mixture was stirred at $50{ }^{\circ} \mathrm{C}$ for $1 \mathrm{~h}$ and then cooled to RT. The precipitates were isolated by filtration under air and washed with $\mathrm{EtOH}$ and diethyl ether. The product was suspended in $\mathrm{EtOH}(20 \mathrm{~mL})$ and $\mathrm{NEt}_{4} \mathrm{OH}$ $(190 \mu \mathrm{L}, 1.5 \mathrm{M}$ in $\mathrm{MeOH}$ ) was added and stirred for $1 \mathrm{~h}$ at $\mathrm{RT}$. After concentrating the solution under reduced pressure, the product was isolated by filtration. Washing with ethanol and diethyl ether gave a brown powder. Yield: $135 \mathrm{mg}$ (97\%). HRMSESI (negative mode): $m / z$ calculated for $\mathrm{C}_{46} \mathrm{H}_{47} \mathrm{~B}_{2} \mathrm{Fe}_{2} \mathrm{~N}_{8} \mathrm{O}_{9}[\mathrm{M}]$ : 989.2350; found: 989.2377 . IR: $1663,1605,1550,1444,1406$, 1333, 1223, 1201, 1081, 1034, 980, 924, 839, 782, 696, 651, 622, 549 . Single crystals were obtained by slow diffusion of pentane into a solution of complex 5 in $\mathrm{CHCl}_{3}$.

Complex 6: $\mathrm{Fe}(\mathrm{OTf})_{2}(113.6 \mathrm{mg}, 321 \mu \mathrm{mol})$ was added to a solution of 2,6-diformyl-4-bromo-phenol dioxime $(100 \mathrm{mg}$, $386 \mu \mathrm{mol}$ ) and 4-pyridylboronic acid ( $36 \mathrm{mg}, 257 \mu \mathrm{mol}$ ) in $\mathrm{MeOH}$ $(20 \mathrm{~mL})$ in the glovebox. The reaction mixture was stirred at $50^{\circ} \mathrm{C}$ for $1 \mathrm{~h}$ and then cooled to RT. The precipitates were isolated by filtration under air and washed with $\mathrm{EtOH}$ and diethyl ether. The product was suspended in $\mathrm{EtOH}(20 \mathrm{~mL})$ and $\mathrm{NEt}_{4} \mathrm{OH}(100 \mu \mathrm{L}$, $1.5 \mathrm{M}$ in $\mathrm{MeOH}$ ) was added and stirred for $1 \mathrm{~h}$ at RT. After concentrating the solution under reduced pressure, the product was isolated by filtration. Washing with ethanol and diethyl ether gave a brown powder. Yield: $130 \mathrm{mg}(96 \%)$. HRMS-ESI (negative mode): $m / z$ calculated for $\mathrm{C}_{34} \mathrm{H}_{20} \mathrm{~B}_{2} \mathrm{Br}_{3} \mathrm{Fe}_{2} \mathrm{~N}_{8} \mathrm{O}_{9}$ [M]: 1054.7790; found: 1054.7789. IR: 1595, 1546, 1480, 1426, 1321, 1202, 1073, $1036,979,948,888,815,780,751,685,649$. Single crystals were obtained by slow diffusion of pentane into a solution of complex 6 in THF.

Complex 7: A solution of $\mathrm{Fe}(\mathrm{OTf})_{2}(57 \mathrm{mg}, 160 \mu \mathrm{mol})$ and $\mathrm{Fe}(\mathrm{OTf})_{3}(80 \mathrm{mg}, 160 \mu \mathrm{mol})$ in $\mathrm{MeOH}(10 \mathrm{~mL})$ was added to a solution of 2,6-diformyl-4-tert-butyl-phenol dioxime (100 mg, $423 \mu \mathrm{mol})$ and 4-pyridylboronic acid $(39.5 \mathrm{mg}, 321 \mu \mathrm{mol})$ in $\mathrm{MeOH}(10 \mathrm{~mL})$ and heated to reflux for $2 \mathrm{~h}$. The solution was cooled to RT and $\mathrm{NEt}_{4} \mathrm{OH}$ solution ( $100 \mu \mathrm{L}, 1.5 \mathrm{M}$ in $\left.\mathrm{MeOH}\right)$ was added and stirred for $1 \mathrm{~h}$. The solvent was evaporated to dryness and the product was purified by silica gel column chromatography (EtOAc) to obtain a black powder. Yield: $82 \mathrm{mg}(65 \%)$. HRMS-ESI (positive mode): $\mathrm{m} / \mathrm{z}$ calculated for $\mathrm{C}_{46} \mathrm{H}_{48} \mathrm{~B}_{2} \mathrm{Fe}_{2} \mathrm{~N}_{8} \mathrm{O}_{9}[\mathrm{M}+\mathrm{H}]^{+}$ 990.2446; found: 990.2458 . IR: 1724, 1673, 1605, 1577, 1452, $1308,1259,1230,1210,1179,1099,1037,927,844,792,762$, $697,644,582,563$. Single crystals were obtained by slow diffusion of diisopropyl ether into a solution of complex 7 in THF.

Complex 8: A solution of $\mathrm{Fe}(\mathrm{OTf})_{2}(45 \mathrm{mg}, 127 \mu \mathrm{mol})$ and $\mathrm{Fe}(\mathrm{OTf})_{3}(64.7 \mathrm{mg}, 127 \mu \mathrm{mol})$ in $\mathrm{MeOH}(10 \mathrm{~mL})$ was added to a solution of 2,6-diformyl-4-bromo-phenol dioxime (100 mg, $386 \mu \mathrm{mol}$ ) and 4-pyridylboronic acid ( $36 \mathrm{mg}, 257 \mu \mathrm{mol}$ ) in $\mathrm{MeOH}$ $(10 \mathrm{~mL})$ and heated to reflux for $2 \mathrm{~h}$. The solution was cooled to $\mathrm{RT}$ and $\mathrm{NEt}_{4} \mathrm{OH}$ solution ( $100 \mu \mathrm{L}, 1.5 \mathrm{M}$ in $\mathrm{MeOH}$ ) was added and stirred for $1 \mathrm{~h}$. The solvent was evaporated to dryness and the product was purified by a silica gel column chromatography (EtOAc:MeOH, 25:1) to obtain a black powder. Yield: $49.5 \mathrm{mg}$ (36\%) HRMS-ESI (positive mode): $\mathrm{m} / \mathrm{z}$ calculated for $\mathrm{C}_{34} \mathrm{H}_{21} \mathrm{~B}_{2} \mathrm{Br}_{3} \mathrm{Fe}_{2} \mathrm{~N}_{8} \mathrm{O}_{9}[\mathrm{M}+\mathrm{H}]^{+}$: 1055.7870 ; found: 1055.7880 . IR: 1708, 1598, 1547, 1491, 1424, 1323, 1214, 1167, 1028, 986, 896, $780,703,637,539$. Single crystals were obtained by slow evaporation of of a solution of complex 8 in THF/acetonitrile.

Complex 9: A solution of $\mathrm{Fe}(\mathrm{OTf})_{3}(70.9 \mathrm{mg}, 140 \mu \mathrm{mol})$ and $\mathrm{Zn}(\mathrm{OTf})_{2}(51.25 \mathrm{mg}, 140 \mu \mathrm{mol})$ in $\mathrm{MeOH}(15 \mathrm{~mL})$ was added to a solution of 2,6-diformyl-4-tert-butyl-phenol dioxime (100 mg, $423 \mu \mathrm{mol})$ and 3-pyridylboronic acid $(39.7 \mathrm{mg}, 282 \mu \mathrm{mol})$ in dichloromethane $(15 \mathrm{~mL})$ and heated to reflux for $2 \mathrm{~h}$. The solution was cooled to RT and $\mathrm{NEt}_{4} \mathrm{OH}$ solution ( $100 \mu \mathrm{L}, 1.5 \mathrm{M}$ in $\left.\mathrm{MeOH}\right)$ was added and stirred for $1 \mathrm{~h}$. The solvent was evaporated to dryness and the product was purified by silica gel column chromatography (EtOAc) to obtain a black powder (133 mg, 94\%). HRMS-ESI (positive mode): $\mathrm{m} / \mathrm{Z}$ calculated for $\mathrm{C}_{46} \mathrm{H}_{49} \mathrm{~B}_{2} \mathrm{FeZnN}{ }_{8} \mathrm{O}_{9}[\mathrm{M}+2 \mathrm{H}]^{+}$: 999.2449; found: 999.2444 IR: 1606, 1583, 1561, 1398, 1258, 1231, 1171, 1094, 937, 841, 787, 765, 632,516 . Single crystals were obtained by slow diffusion of $\mathrm{Et}_{2} \mathrm{O}$ into a solution of complex 9 in DCM. 


\section{WILEY-VCH}

Complex 10: A solution of $\mathrm{Fe}(\mathrm{OTf})_{2}$ ( $\left.226 \mathrm{mg}, 640 \mu \mathrm{mol}\right)$ and $\mathrm{Fe}(\mathrm{OTf})_{3}(321 \mathrm{mg}, 640 \mu \mathrm{mol})$ in $\mathrm{MeOH}(10 \mathrm{~mL})$ was added to a solution of 2,6-diformyl-4-bromo-phenol dioxime (500 mg, 1930 $\mu \mathrm{mol}$ ) and 4-bromobenzeneboronic acid (258 mg, $1280 \mu \mathrm{mol})$ and in $\mathrm{MeOH}(10 \mathrm{~mL})$. Subsequently, $\mathrm{NEt}_{4} \mathrm{OH}$ solution $(400 \mu \mathrm{L}, 1.5 \mathrm{M}$ in $\mathrm{MeOH}$ ) was added and the mixture was heated to reflux for $2 \mathrm{~h}$. After cooling to RT, the solvent was evaporated to dryness and the product was purified by silica gel column chromatography (DCM) to obtain a black powder. Yield: $667 \mathrm{mg}$ (86\%) HRMS-ESI (posetive mode): $\mathrm{m} / \mathrm{z}$ calculated for $\mathrm{C}_{36} \mathrm{H}_{20} \mathrm{~B}_{2} \mathrm{Br}_{5} \mathrm{Fe}_{2} \mathrm{~N}_{6} \mathrm{O}_{9}$ [M]: 1212.6065; found: 1212.6074. IR: 1708, 1598, 1547, 1491, 1424, 1323, 1214, 1167, 1028, 986, 896, 780, 703, 637, 539. Single crystals were obtained by slow diffusion of $\mathrm{Et}_{2} \mathrm{O}$ into a solution of complex 10 in DMF.

Polymer PCP-1: $\mathrm{Pd}\left(\mathrm{PPh}_{3}\right)_{4}(13.9 \mathrm{mg}, 12 \mu \mathrm{mol})$ was added a solution of complex 10 (50 mg, $40 \mu \mathrm{mol}), 1,4$-phenyldiboronic acid (18 mg, $120 \mu \mathrm{mol})$ and $\mathrm{K}_{2} \mathrm{CO}_{3}(66 \mathrm{mg}, 480 \mu \mathrm{mol})$ in 1,4dioxane: $\mathrm{H}_{2} \mathrm{O}(4: 1)(15 \mathrm{~mL})$ under $\mathrm{N}_{2}$. The solution was sealed and stirred at $110^{\circ} \mathrm{C}$ for $12 \mathrm{~h}$, and then cooled to RT. The product was isolated by filtration, washed with 1,4-dioxane, DMF, water, and diethyl ether to yield a greyish polymer. Yield: $45 \mathrm{mg}$. IR: 1593, 1559, 1481, 1438, 1378, 1296, 1201, 1091, 1045, 1006, 969, 929, $889,787,757,701,670,535$.

X-Ray crystallography: CCDC-1584477 (for 5), 1584478 (for 6), 1584479 (for 7(HOTF) $)$ ), 1584481 (for 8), 1584482 (for 9), and 1584483 (for 10), contain the supplementary crystallographic data for this paper. These data can be obtained free of charge from The Cambridge Crystallographic Data Centre via www.ccdc.cam.ac.uk/data request/cif.

Acknowledgements: The work was supported by the Swiss National Science Foundation and by the Ecole Polytechnique Fédérale de Lausanne (EPFL). We thank Thomas Di Franco for the help with the cyclic voltammetry measurements.

Keywords: clathrochelate complex $\bullet$ iron complex $•$ polymer $•$ cross-coupling $\bullet$ redox activity

[1] Cage Metal Complexes (Eds.: Y. Voloshin, I. Belaya, R. Krämer), Springer International Publishing AG, Cham, 2017.

[2] S. Khanra, T. Weyhermuller, E. Bill, P. Chaudhuri, Inorg. Chem. 2006, 45, 5911-5923.

[3] M. Pascu, M. Marmier, C. Schouwey, R. Scopelliti, J. J. Holstein, G. Bricogne, K. Severin, Chem. Eur. J. 2014, 20, 5592-5600.

[4] For reviews about metalloligands see: a) S. Srivastava, R. Gupta, CrystEngComm 2016, 18, 9185-9208; b) L. LI, D. J. Fanna, N. D. Shepherd, L. F. Lindoy, F. Li, J. Incl. Phenom. Macrocycl. Chem. 2015, 82, 3-12; C) H. Li, Z.-J. Yao, D. Liu, G.-X. Jin, Coord. Chem. Rev. 2015, 293-294, 139-157; d) M. D. Wise, K. Severin, Chimia 2015, 69, 191195; e) G. Kumar and R. Gupta, Chem. Soc. Rev. 2013, 42, 9403-9453; f) M. C. Das, S. Xiang, Z. Zhang, B. Chen, Angew. Chem., Int. Ed. 2011, 50, 10510-10520; g) E. C. Constable, Coord. Chem. Rev., 2008, 252, 842-855.

[5] a) G. Cecot, M. Marmier, S. Geremia, R. De Zorzi, A. V. Vologzhanina, P. Pattison, E. Solari, F. F. Tirani, R. Scopelliti, K. Severin, J. Am. Chem. Soc. $2017,139,8371-8381$; b) M. Marmier, G. Cecot, A. V. Vologzhanina, J. L. Bila, I. Zivkovoc, H. M. Ronnow, B. Nafradi, E. Solari, P. Pattison, R. Scopelliti, K. Severin, Dalton Trans. 2016, 45, 1550715516; c) M. Marmier, M. D. Wise, J. J. Holstein, P. Pattison, K. Schenk, E. Solari, R. Scopelliti, K. Severin, Inorg. Chem. 2016, 55, 4006-4015; d)
M. Marmier, G. Cecot, B. F. Curchot, P. Pattison, E. Solari, R. Scopelliti, K. Severin, Dalton Trans. 2016, 45, 8422-8427.

[6] C. Ge, J. Zhang, Z. Qin, P. Zhang, R. Zhang, H. Zhao, Y. Wang, X. Zhang, Inorg. Chim. Acta 2017, 463, 134-141.

[7] For selected examples see: a) G. E. Zelinskii, S. V. Dudkin, A. S. Chuprin, A. S. Belov, V. V. Novikov, A. V. Vologzhanina, E. G. Lebed, Y. Z. Voloshin, Inorg. Chim. Acta 2016, 453, 210-221; b) G. E. Zelinskii, A. S. Chuprin, A. A. Pavlov, A. V. Vologzhanina, E. G. Lebed, Y. V. Zubavichus, Y. Z. Voloshin, Inorg. Chim. Acta 2017, 463, 29-35; b) G. E. Zelinskii, A. S. Belov, E. G. Lebed, A. V. Vologzhanina, V. V. Novikov, Y. Z. Voloshin, Inorg. Chim. Acta 2016, 440, 154-164; c) I. G. Belaya, S. V. Svidlov, A. V. Dolganov, G. E. Zelinskii, T. V. Potapova, A. V. Vologzhanina, O. A. Varzatskii, Y. N. Bubnov, Y. Z. Voloshin, Dalton Trans. 2013, 42, 13667-13678.

[8] For recent reviews see: a) W. Zhang, B. Agulia, S. Ma, J. Mater. Chem. A 2017, 5, 8795-8824; b) S. Das, P. Heasman, T. Ben, S. Qiu, Chem. Rev. 2017, 117, 1515-1563; c) U. Díaz, A. Corma, Coord. Chem. Rev. 2016, 311, 85-124; d) U. H. F. Bunz, K. Seehafer, F. L. Geyer, M. Bender, I. Braun, E. Smarsly, J. Freudenberg, Macromol. Rapid Commun. 2014, 35, 1466-1496; e) C. Xu, N. Hedin, Materials Today, 2014, 17, 397-403; f) Z. Xiang, D. Cao, J. Mater. Chem. A. 2013, 1 , 2691-2718; g) T. Beng, S. Qiu, CrystEngComm 2013, 15, 17-26; h) Y. Xu, S. Jin, H. Xu, A. Nagai, D. Jiang, Chem. Soc. Rev. 2013, 42, 80128031; i) R. Dawson, A. I. Cooper, D. J. Adams, Progr. Polym. Sci. 2012, $37,530-563$.

[9] For examples of polymers based on inorganic monomers see: a) $\mathrm{H}$. Jia, Y. Yao, Y. Gao, D. Lu, P. Du, Chem. Commun. 2016, 52, 13483-13486; b) D. Wang, S. Feng, H. Liu, Chem. Eur. J. 2016, 22, 14319-14327; c) Y. Xie, T.-T. Wang, X.-H. Liu, K. Zou, W.-Q. Deng, Nature Commun. 2013, 4, 1960; d) R. K. Totten, Y.-S. Kim, M. H. Weston, O. K. Farha, J. T. Hupp, S. T. Nguyen, J. Am. Chem. Soc. 2013, 135, 11720-11723; e) J.-X. Jiang, C. Wang, A. Laybourn, T. Hasell, R. Clowes, Y. Z. Khimyak, J. Xiao, S. J. Higgins, D. J. Adams, A. I Cooper, Angew. Chem. Int. Ed. 2011, 50, 1072-1075; f) L. Chen, Y. Yang, D. Jiang, J. Am. Chem. Soc. 2010, 132, 9138-9143.

[10] a) J. Lozada, Z. Liu, D. M. Perrin, J. Org. Chem. 2014, 79, 5365-5368; b) G. A. Molander, B. Canturk, L. E. Kennedy, J. Org. Chem. 2009, 74, 973-980.

[11] For polymers containing mononuclear clathrochelate complexes see: a) B. Alameddine, S. Shetty, N. Baig, S. Al-Mousawi, F. Al-Sagheer, Polymer 2017, 122, 202-207; b) W. Liu, W. Huang, M. Pink, D. Lee, J. Am. Chem. Soc. 2010, 132, 11844-11846.

[12] D. M. D'Alessandro, Chem. Commun. 2016, 52, 8957-8971.

[13] L. Patiny, A. Borel, J. Chem. Inf. Model. 2013, 53, 1223-1228. 
WILEY-VCH

Entry for the Table of Contents

\section{FULL PAPER}

Dinuclear iron clathrochelate

complexes are described. The easy-

to-access complexes are redox active,

robust, and they can be decorated

with functional groups. These

properties make them interesting

building blocks for supramolecular

chemistry and materials science.

\section{Cage complexes*}

José L. Bila, Mathieu Marmier,

Konstantin O. Zhurov, Rosario Scopelliti,

Ivica Živković, Henrik M. Rønnow, Elahi

S. Noore. Andrzej Sienkiewicz, Cornel

Fink and Kay Severin*

Page No. - Page No.

Homo- and Heterodinuclear Iron

Clathrochelate Complexes with

Functional Groups in the Ligand

Periphery

*one or two words that highlight the emphasis of the paper or the field of the study

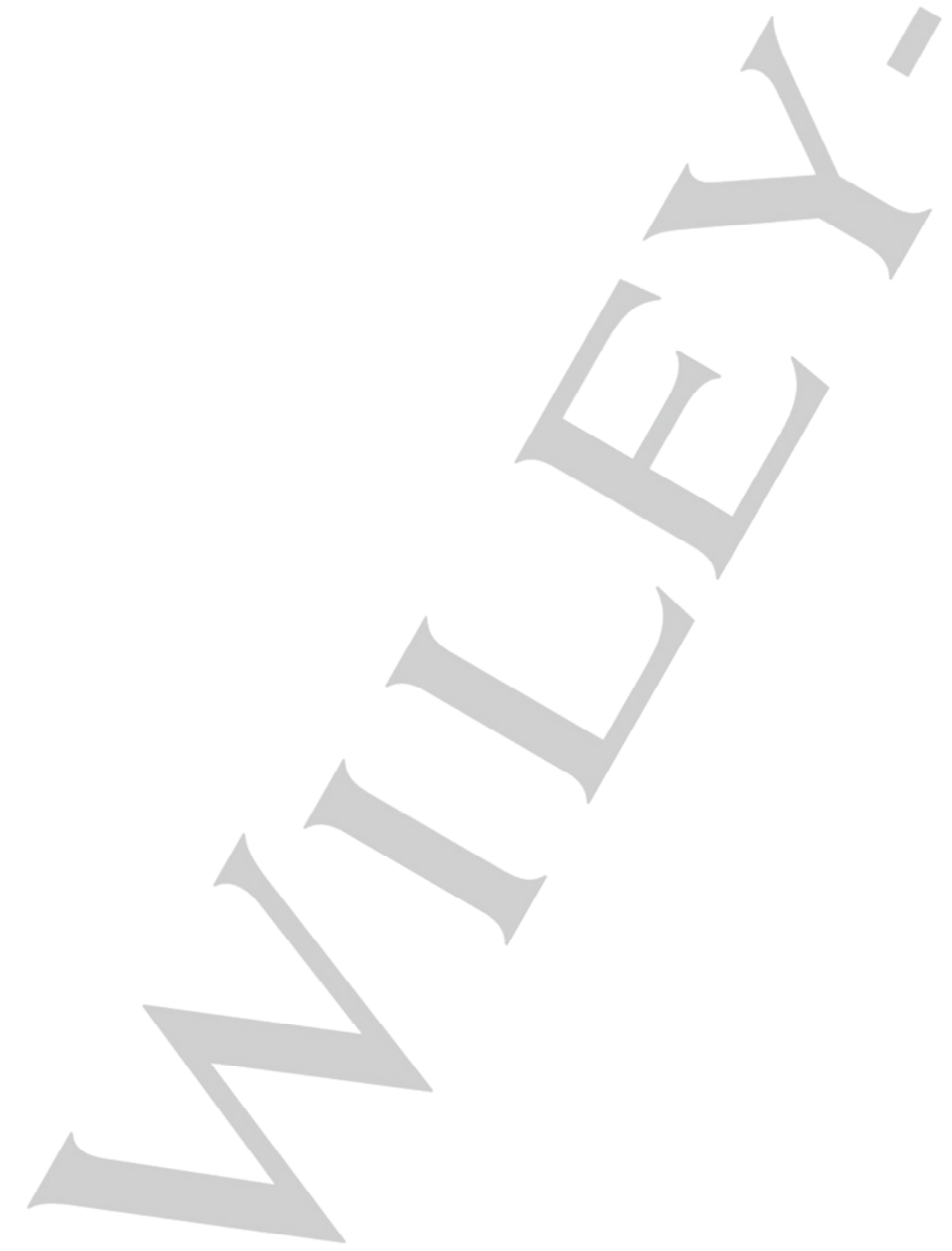

